\title{
Effect of Modified and Nonmodified Carbon Nanotubes on the Rheological Behavior of High Density Polyethylene Nanocomposite
}

\author{
Adewunmi A. Ahmad, ${ }^{1}$ Abdulhadi A. Al-Juhani, ${ }^{1}$ Selvin Thomas, ${ }^{2}$ \\ S. K. De, ${ }^{1}$ and Muataz A. Atieh ${ }^{1}$ \\ ${ }^{1}$ Department of Chemical Engineering, King Fahd University of Petroleum and Minerals (KFUPM) P.O. Box 5050, \\ Dhahran 31261, Saudi Arabia \\ ${ }^{2}$ Chemical Engineering Technology Department \& Yanbu Research Center, Yanbu Industrial College, P.O. Box 30436, \\ Yanbu Industrial City 21477, Saudi Arabia
}

Correspondence should be addressed to Muataz A. Atieh; motazali@kfupm.edu.sa

Received 31 March 2013; Revised 2 September 2013; Accepted 8 September 2013

Academic Editor: Sulin Zhang

Copyright (C) 2013 Adewunmi A. Ahmad et al. This is an open access article distributed under the Creative Commons Attribution License, which permits unrestricted use, distribution, and reproduction in any medium, provided the original work is properly cited.

\begin{abstract}
This paper reports the results of studies on the rheological behavior of nanocomposites of high density polyethylene (HDPE) with pristine multiwall carbon nanotubes $(\mathrm{CNT})$ as well as phenol and 1-octadecanol (C18) functionalized CNT at 1, 2, 3, 4, 5, and $7 \mathrm{wt} \%$ loading. The viscosity reduction at $1 \mathrm{wt} \% \mathrm{CNT}$ follows the order, pristine $\mathrm{CNT}<$ phenol functionalized $\mathrm{CNT}<\mathrm{C} 18$ functionalized CNT. As the filler loading increases from 1 to 2, 3, and 4 wt\%, neat HDPE and filled HDPE systems show similar moduli and viscosity, particularly in the low frequency region. As the filler loading increases further to 5 and $7 \mathrm{wt} \%$, the viscosity and moduli become greater than the neat HDPE. The storage modulus, $\tan \delta$, and the Cole-Cole plots show that CNT network formation occurs at higher CNT loading. The critical CNT loading or the rheological percolation threshold, where network formation occurs is found to be strongly dependant on the functionalization of CNT. For pristine CNT, the rheological percolation threshold is around $4 \mathrm{wt} \%$, but for functionalized CNT it is around $7 \mathrm{wt} \%$. The surface morphologies of CNT and functionalized CNT at $1 \mathrm{wt} \%$ loading showed good dispersion while at $7 \mathrm{wt} \%$ loading, dispersion was also achieved, but there are few regions with agglomeration of CNT.
\end{abstract}

\section{Introduction}

High density polyethylene (HDPE) is a commodity thermoplastic polymer and is widely used in different applications due to its outstanding features such as regular chain structure, combination of low cost and low energy demand for processing, excellent biocompatibility, and good mechanical properties $[1,2]$. Properties of HDPE can be further manipulated by the addition of organic or inorganic particles into the polymer matrix $[3,4]$. The nanofiller reinforced HDPE composites have been studied for various fillers like nanoclay, metal oxide nano particles, and carbon nanotubes [5-7].

The dispersion of carbon nanotubes is a great challenge in the fabrication of polymer composites. Good dispersion of CNT into any polymer matrix is very difficult to achieve. Techniques such as surfactant-assisted processing, solutionevaporation methods with high-energy sonication, and covalent functionalization of the nanotubes with a polymer matrix have been exploited, but good dispersion was not always achievable in all polymer matrices [8-10]. Enhancement of interfacial interaction on incorporation of surfactants as the processing aid was reported by Gong et al. in epoxy/CNT composites [11]. They observed an increase in glass transition temperature from $63^{\circ} \mathrm{C}$ to $88^{\circ} \mathrm{C}$ and $30 \%$ increase in elastic modulus at $1 \mathrm{wt} \%$ loading of surfactant modified CNT, even though good dispersion of CNT was still not achieved. Zou et al. found that HDPE/CNT composites fabricated at higher screw speed provide improved dispersion of CNT in HDPE 
[12]. Ha et al. studied the effect of the molecular weight of HDPE and polycarbonate (PC) on the dispersion of CNT, and rheological properties of the composites [13]. The use of a high melt viscosity polymer as the matrix material restricted the mobility of CNT, and also hindered the dispersion of CNT due to the high entanglement density of the polymer matrix compared to the low molecular weight matrices.

Poor dispersion of nanoparticles in the polymer matrices leads to formation of aggregates and filler networks, particularly at higher filler loadings. Osman and Atallah studied the rheological behaviour of HDPE composites with surface treated and untreated noncolloidal calcium carbonate $\left(\mathrm{CaCO}_{3}\right)$ particles and observed particle agglomeration and cluster formation with increase in filler volume fraction [14]. While the presence of clusters increased the viscosity, surface coating caused a reduction in the extent of polymer chain entanglements and drop in viscosity. Tang et al. reported significant changes in rheological properties for the HDPE/organoclay composites compatibilized with maleic anhydride grafted PE [6]. Non-Newtonian viscosity behavior was observed at all organoclay loadings, and the lowfrequency storage modulus showed a plateau and storage and loss moduli increased with increase in organoclay loading.

McNallyet al. prepared PE/CNT composites with weight fractions ranging from 0.1 to $10 \mathrm{wt} \%$ using melt extrusion and studied the rheological and electrical properties [15]. The storage modulus $\left(G^{\prime}\right)$ versus frequency curves approached a plateau between 8.5 and $10 \mathrm{wt} \%$ indicating the rheological percolation threshold with the formation of an interconnected nanotube structure, indicative of "pseudo-solid-like" behavior. The high percolation threshold was attributed by the authors to the coating of the PE over CNT and geometry of the die which reduced the entanglements. Valentino et al. studied the melt rheological investigations of melt mixed HDPE/CNT composites, and the percolation threshold was obtained in between 1 and $2.5 \mathrm{wt} \%$ of CNT loading [16].

A drop in the viscosity of nanoparticle-filled polymer melts prepared by blending organic nanoparticles, either synthesized by intramolecular cross-linking of single poly(styrene) (PS) chains or using branched, dendritic poly(ethylene) (PE), with linear atactic PS over a large concentration range was reported recently [17-19]. Merkel et al. attributed the decrease in the viscosity to the excluded free volume induced around the nanoparticles [20]. However, Kharchenko et al. reported a significant increase in the viscosity of CNT-filled polymer materials, even at very low loadings [21]. A similar increase in viscosity has been reported in the case of clay-polymer nanocomposites by Ren and Krishnamoorti [22]. Therefore, a conclusive outcome with respect to the behavior of viscosity is not yet achieved in nano filled polymer composites.

The role of surface modification and the effect of nanofiller loading on the rheological behavior of the polymer nanocomposites have not been resolved as yet, and there exists scope for research in this area and with this objective in mind, the present investigation was undertaken. The paper reports the results of studies on the effects of functionalization of CNT and its loading on the rheological behavior of HDPE/CNT composites.

\section{Materials and Methods}

The CNT was purchased from Cheap Tube Inc., 112 Mercury Drive, Brattleboro, VT 05301, USA. The specifications of CNT are as follows: range of diameter $20-30 \mathrm{~nm}$, length of the tube $10-30 \mu \mathrm{m}$, and purity $>95 \mathrm{wt} \%$. The density of CNT is $2.1 \mathrm{~g} / \mathrm{cm}^{3}$. The HDPE pellets (HDPE HMA 014) were obtained from ExxonMobil Corporation, USA. The melt flow index and density of the HDPE pellets are $4.0 \mathrm{~g} / 10 \mathrm{~min}$ (ASTM D4101-10) and $0.960 \mathrm{~g} / \mathrm{cm}^{3}$, respectively. The CNT surface was functionalized with phenol and 1-octadecanol (both were purchased from Sigma Aldrich, USA) by techniques as reported earlier by Thomas et al. [23, 24].

HDPE was melt blended with 1, 2, 3, 4, 5, and $7 \mathrm{wt} \%$ of pristine and functionalized CNT using a Brabender mixer at $150^{\circ} \mathrm{C}$ for $10 \mathrm{~min}$ at a rotor speed of $120 \mathrm{rpm}$. The blended mixtures were then hot pressed at $150^{\circ} \mathrm{C}$ under $9 \mathrm{MPa}$ using Carver hot-press.

ARES controlled strain rheometer (TA Instruments) was used for all rheological measurements. It was equipped with heavy transducer (range $0.02-20 \mathrm{~N}$ for normal force; $2 \times 10^{-5}$ to $2 \times 10^{-1} \mathrm{Nm}$ for torque). The linear and nonlinear viscoelastic experiments were performed using $25 \mathrm{~mm}$ parallel plates. The plates were heated for at least $20 \mathrm{~min}$ to stabilize the temperature. For reproducibility of results, a presteady shear rate of $0.1 \mathrm{~s}^{-1}$ was applied for $20 \mathrm{~s}$ for all the tests in the parallel plates and time delay of $100 \mathrm{~s}$ before the actual tests. Dynamic oscillation frequency sweep of $0.015-100 \mathrm{rad} / \mathrm{s}$ in the linear viscoelastic range (strain $2 \%$ ) with parallel plate under nitrogen atmosphere were done at $200^{\circ} \mathrm{C}$. The samples were left to equilibrate for $5 \mathrm{~min}$ prior to each measurement. The steady shear viscosity measurements of the samples were done in parallel-plate geometry with a diameter of $25 \mathrm{~mm}$ at $200^{\circ} \mathrm{C}$ at strain rates ranging from 0.01 to $100 \mathrm{~s}^{-1}$.

\section{Results}

Figure 1 shows the frequency dependence of the dynamic viscosity at different loadings of CNT and modified CNT in the HDPE composites. HDPE shows the typical rheological flow in the experimental frequencies. Incorporation of CNT at $1 \mathrm{wt} \%$ loading reduces the dynamic viscosity in the low frequency region. As for the $2 \mathrm{wt} \%$ loading, the dynamic viscosity of functionalized CNT slightly reduces but the pristine CNT viscosity increases. In the case of $3 \mathrm{wt} \%$ loading of the nanofillers, the viscosity of HDPE increases in the whole range of frequencies studied, but the effect is less pronounced in the case of functionalized CNT. In the case of $4 \mathrm{wt} \%$ loading, the viscosity of HDPE increases in the whole range of frequencies, but the increase is well noticed in the pristine CNT and phenol. As the filler loading increases to 5 and $7 \mathrm{wt} \%$, the dominant role of the hydrodynamic factor (i.e., increase in relative effect of hydrodynamic forces with 


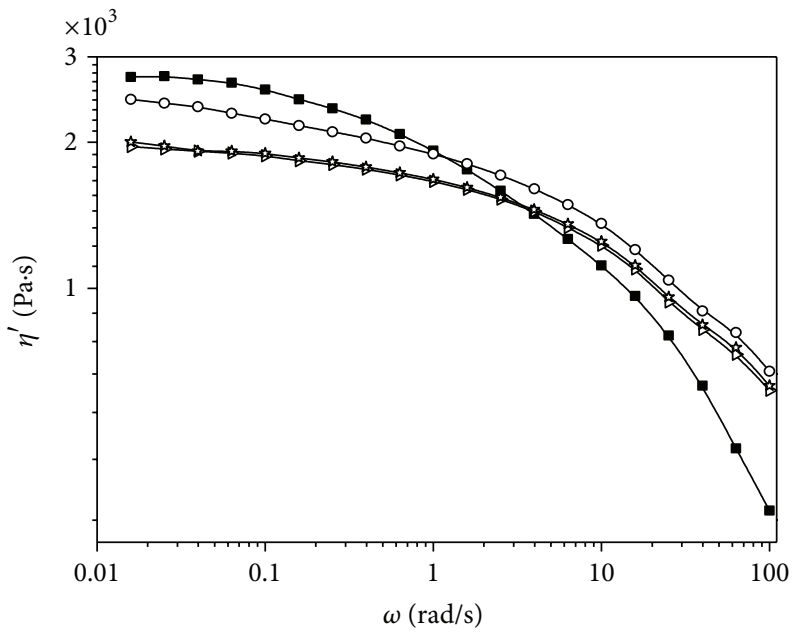

(a)

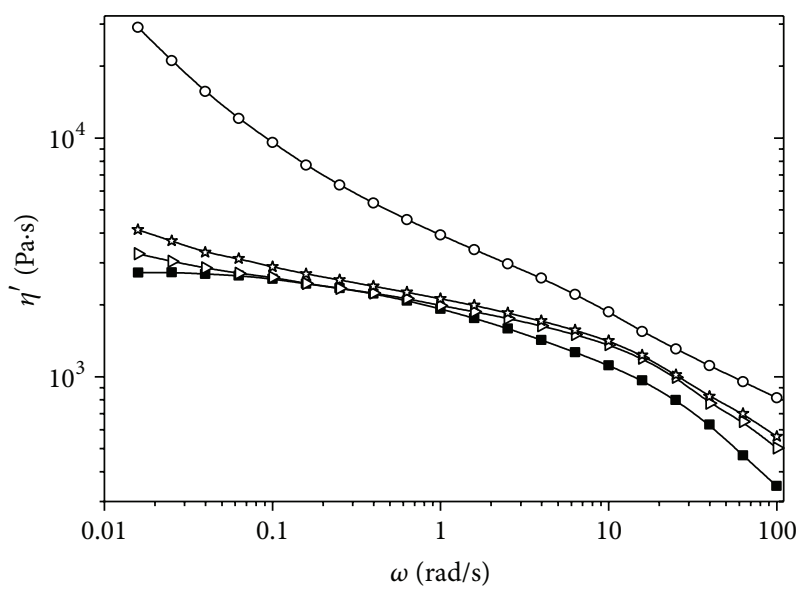

(c)

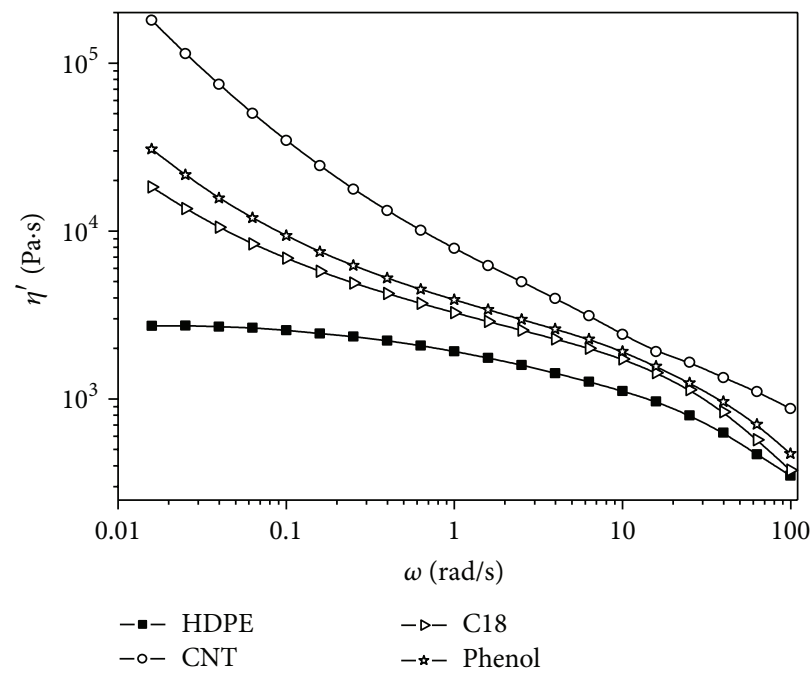

(e)

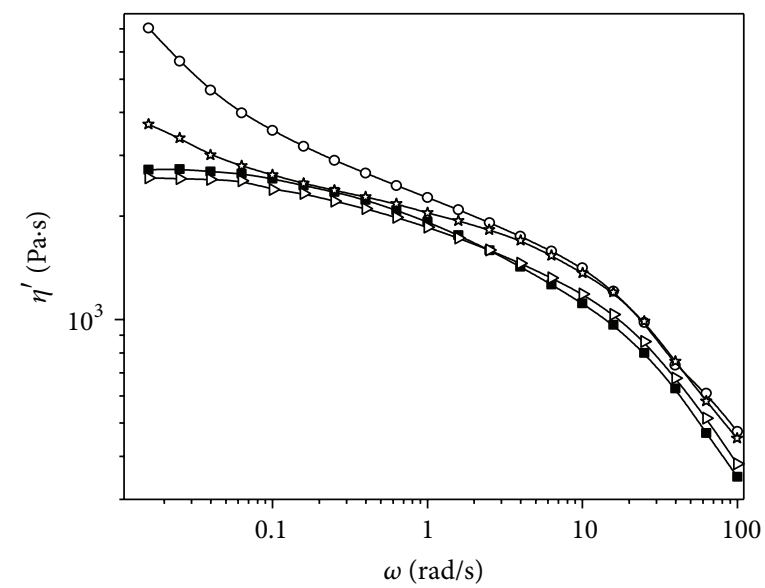

(b)

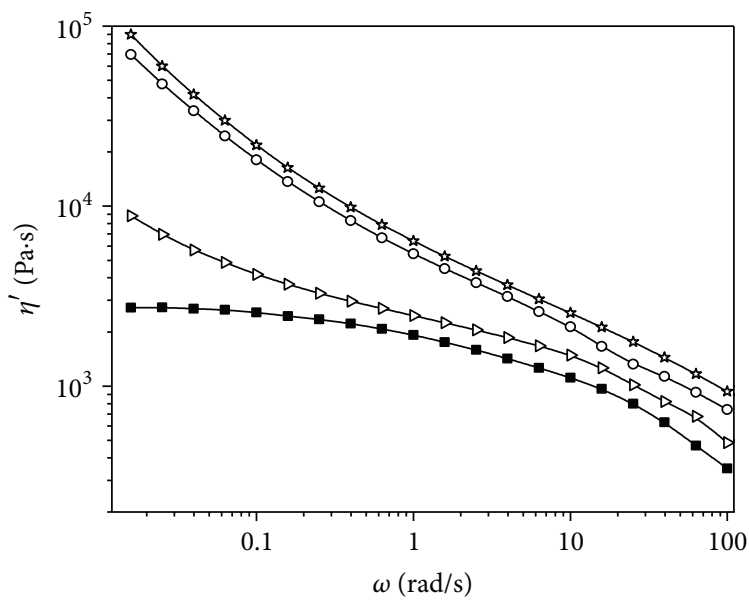

(d)

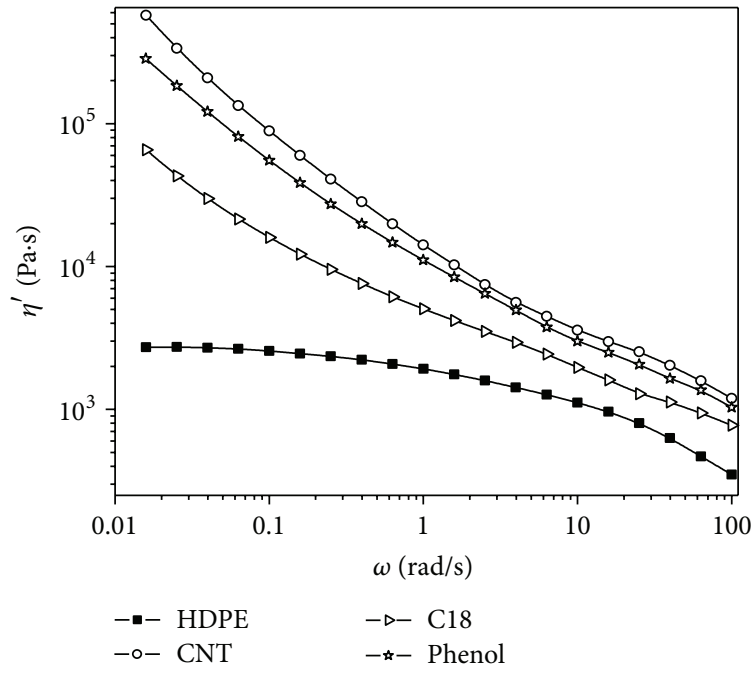

(f)

FIGURE 1: Variation of dynamic viscosity of HDPE composite with frequency. (a) 1, (b) 2, (c) 3, (d) 4, (e) 5, and (f) 7 wt\% loading of nanofiller. 


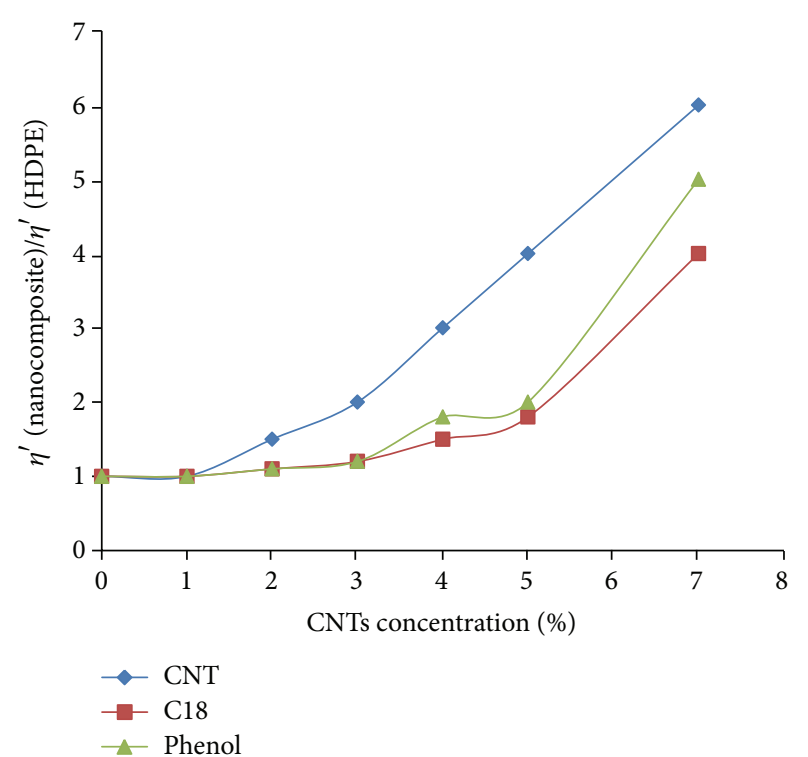

FIgURE 2: Dependence of the ratio of the $\left(\eta^{\prime}\right)_{\text {composite }} /\left(\eta^{\prime}\right)_{\mathrm{HDPE}}$ at $1 \mathrm{rad} / \mathrm{s}$ on the nano filler loading.

respect to the Brownian contribution) becomes more apparent, and viscosity showed a sharp increase at all frequencies on incorporation of both CNT and modified CNT.

Figure 2 shows the variation of the viscosity ratio versus the concentration of the CNT at a frequency of $1 \mathrm{~Hz}$. For the $1 \mathrm{wt} \%$ of modified CNT, the viscosity ratio drops to less than one indicating a drop in viscosity. The composites with functionalized CNT show lower viscosity ratio as compared to the unfunctionalized CNT at all concentrations.

The steady shear viscosity against strain rate is given in Figure 3. As in dynamic viscosity measurements, $1 \mathrm{wt} \%$ loading of pristine and functionalized CNT show reduction in viscosity compared to $\mathrm{HDPE}$. At $2 \mathrm{wt} \%$ loading, the viscosity of $\mathrm{C} 18$ slightly reduced than neat HDPE, while the viscosity of phenol is almost the same as that of neat HDPE. However, the pristine CNT viscosity increased drastically. The increase in loading to 3 and $4 \mathrm{wt} \%$ reverses the trend, and the viscosity of the composites is higher than the polymer. When the loading becomes 5 and $7 \mathrm{wt} \%$, the viscosity is much higher than HDPE. Moreover, the lower frequency region showed marked difference in viscosities for the different grades of CNT. At higher frequencies there is not much difference in viscosities for HDPE and the composites. Among the two functionalized grades of CNT, the $\mathrm{C} 18$ functionalization showed higher reduction in viscosity compared to the phenol functionalization.

The plots of storage modulus against frequency at different loadings of pristine CNT and functionalized CNT are given in Figure 4. It is interesting to note that in the case of nano filler loading of $1 \mathrm{wt} \%$, neat HDPE shows the highest storage modulus, which decreases on addition of pristine $\mathrm{CNT}$ and functionalized CNT, and the effect is pronounced in the low and medium frequency region. At higher frequencies, however, both filled and unfilled HDPE have similar moduli. This effect is similar to that observed in the case of viscosity changes. At $2 \mathrm{wt} \%$ loading, there is a gradual increase in the storage modulus at low frequency below $0.1 \mathrm{rad} / \mathrm{s}$ while the storage modulus is almost the same for the pristine CNT and functionalized CNT's at higher frequency region. As the nanofiller loading increases to 3 and $4 \mathrm{wt} \%$, storage modulus of the filled system increases sharply, particularly in the low frequency region. In the case of 5 and $7 \mathrm{wt} \%$ loading of nano filler, the increase in storage modulus becomes pronounced and the filled HDPE registers higher storage modulus than the neat HDPE in all frequencies. It is observed that the functionalized CNT shows lower modulus than the pristine CNT at all loadings except at $4 \mathrm{wt} \%$ loading where functionalized phenol exhibited the highest storage modulus. Furthermore, a plateau is observed in the low frequency region at $3 \mathrm{wt} \%$ loading of pristine CNT and $4 \mathrm{wt} \%$ loading of pristine CNT and phenol and the same is observed at 5 and $7 \mathrm{wt} \%$ in the case of functionalized CNT.

Figure 5 shows the plots of $\tan \delta$ versus frequency. For the unfilled HDPE sample, $\tan \delta$ is greater than one and decreases as $\omega$ increases, which is typical for liquid-like materials. At $1 \mathrm{wt} \%$ loading of the nano filler this behavior does not change, regardless of the type of CNT. Likewise, at $2 \mathrm{wt} \%$ loading, $\tan \delta$ of pristine CNT and functionalized CNT is greater than one at low frequency region and then decreases in all cases as frequency reaches maximum. However, at $3 \mathrm{wt} \%$ of pristine CNT, $\tan \delta$ shows a value of less than one and it increases as $\omega$ increases in the low frequency range, until it reaches a maximum. In the case of functionalized $\mathrm{CNT}$, at $3 \mathrm{wt} \%, \tan \delta$ is greater than one and there is a tendency to increase with the increase in frequency in the low frequency region and reach a maximum. As for the $4 \mathrm{wt} \%$ loading, $\tan \delta$ of the pristine CNT and phenol is less than one at low frequency region and remains almost constant as $\omega$ reaches maximum. But at higher loading (i.e., at 5 and $7 \mathrm{wt} \%$ ) of the nano filler, irrespective of whether it is pristine or functionalized, the compositions have $\tan \delta$ less than one and there is sharp increase in $\tan \delta$ with increase in frequency in the low frequency region till the maximum is reached.

Figure 6 presents the plots of $G^{\prime}$ versus $G^{\prime \prime}$, which is a typical Cole-Cole plot. As can be clearly seen from Figure 6, the plots for both filled and unfilled compositions at $1 \mathrm{wt} \%$ of CNT follow the same path, with no changes in the slope. However, the slope in the plots decreases sharply, as the nanofiller concentration exceeds $1 \mathrm{wt} \%$, and this is true for both pristine and functionalized CNT.

The interaction and compatibility of the CNTs in iPP matrices and the morphology of the cross section and profile section of the nanocomposites were investigated. For this purpose, SEM was conducted on fractured surfaces of the nanocomposites for $1.0 \mathrm{wt}$ and $7 \mathrm{wt} \%$ of CNTs, CNTs-C18, and CNTs-Phenol and compared with SEM image of net HDPE as shown in Figures $7(\mathrm{a})-7(\mathrm{~g})$. Although, different fractured surfaces of the composites were scanned for SEM, there was however no clear disparity between the image of net HDPE and images obtained for CNT/HDPE and CNTC18/HDPE in Figures 7(a)-7(e). However, there is a clear difference between the fractured surface of HDPE and the CNT-Phenol/HDPE (Figures 7(f) and 7(g)). 


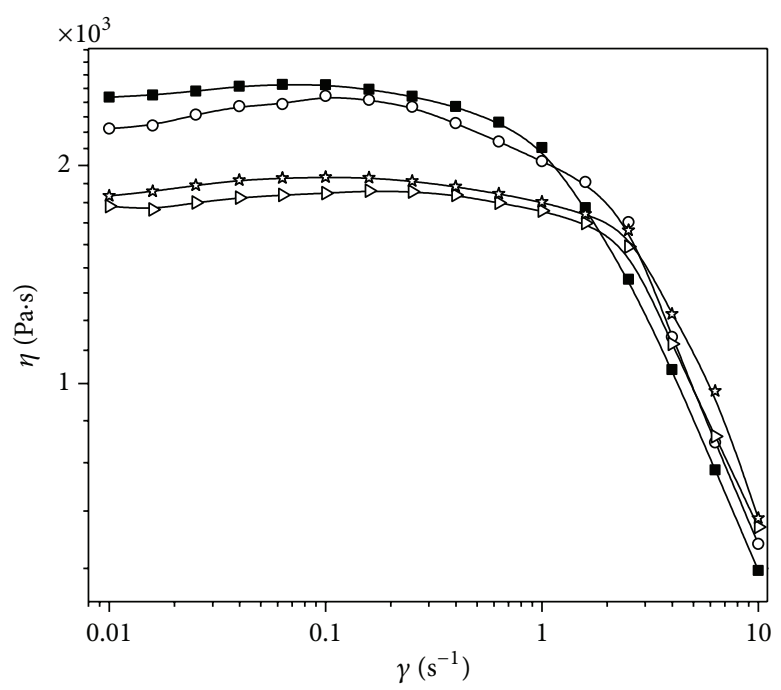

(a)

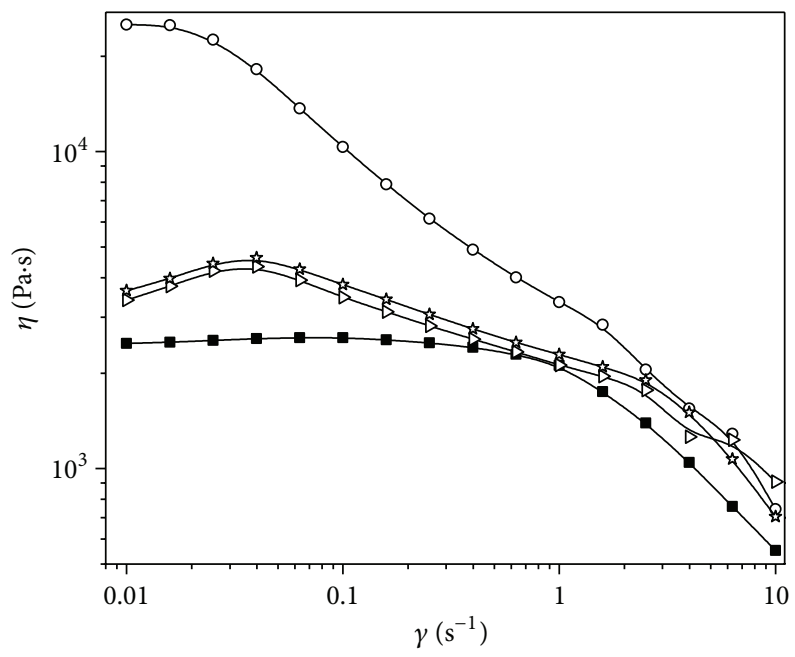

(c)

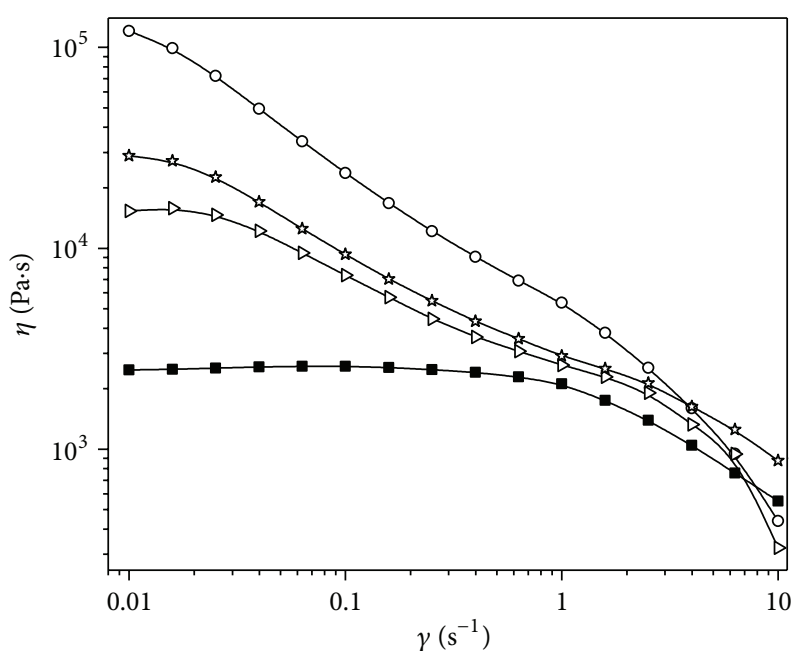

$\rightarrow-$ HDPE $\rightarrow-\mathrm{C} 18$

(e)

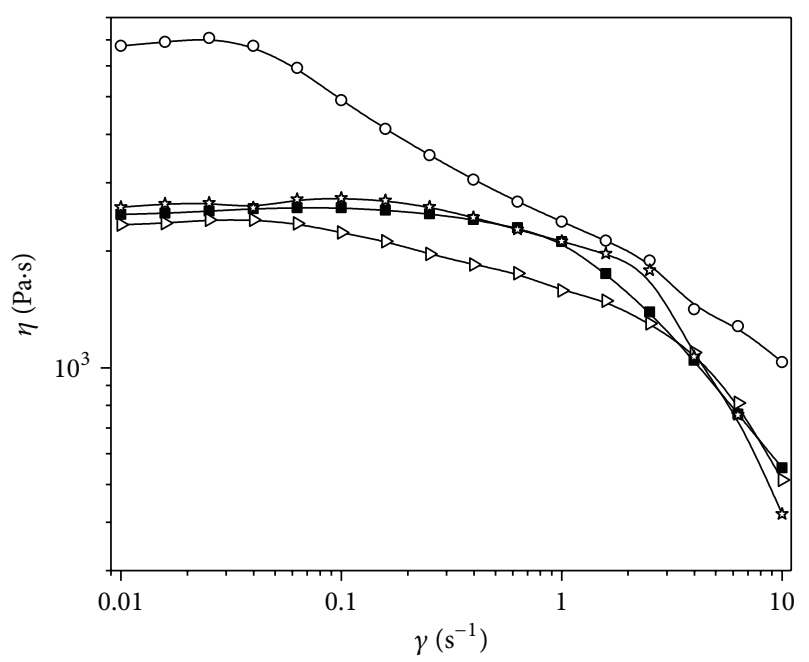

(b)

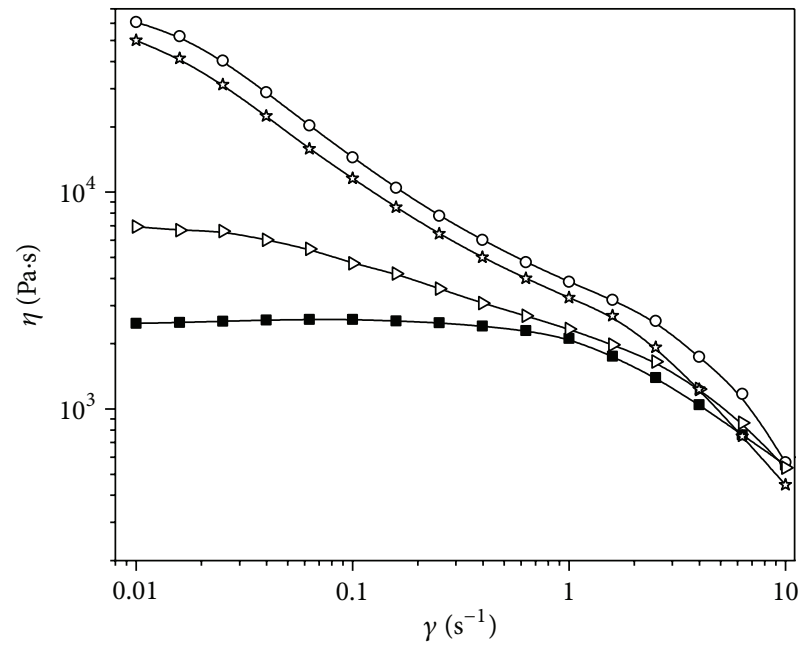

(d)

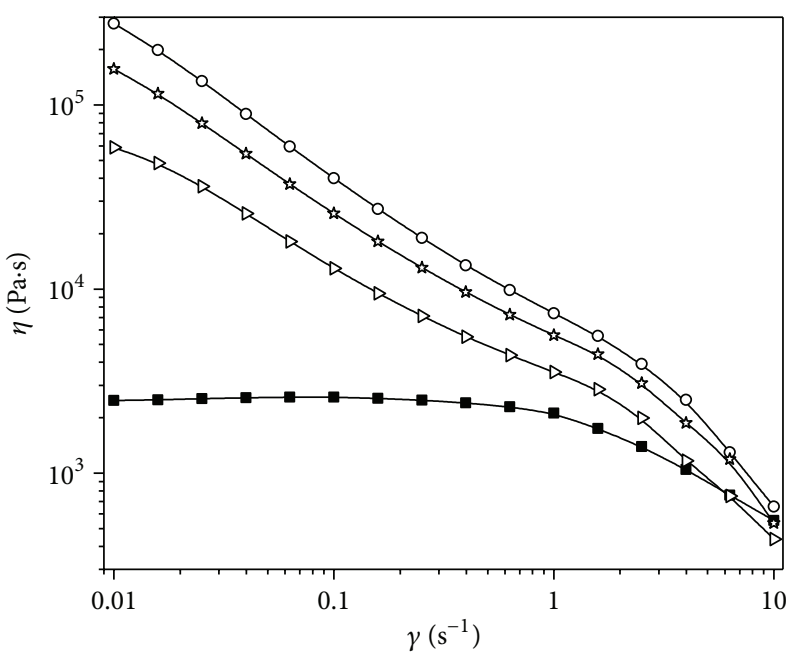

- - HDPE

$\rightarrow-\mathrm{C} 18$

$-\star-$ Phenol

(f)

Figure 3: Variation of steady shear viscosity of HDPE composite with frequency. (a) 1, (b) 2, (c) 3, (d) 4, (e) 5, and (f) 7 wt\% loading of nanofiller. 


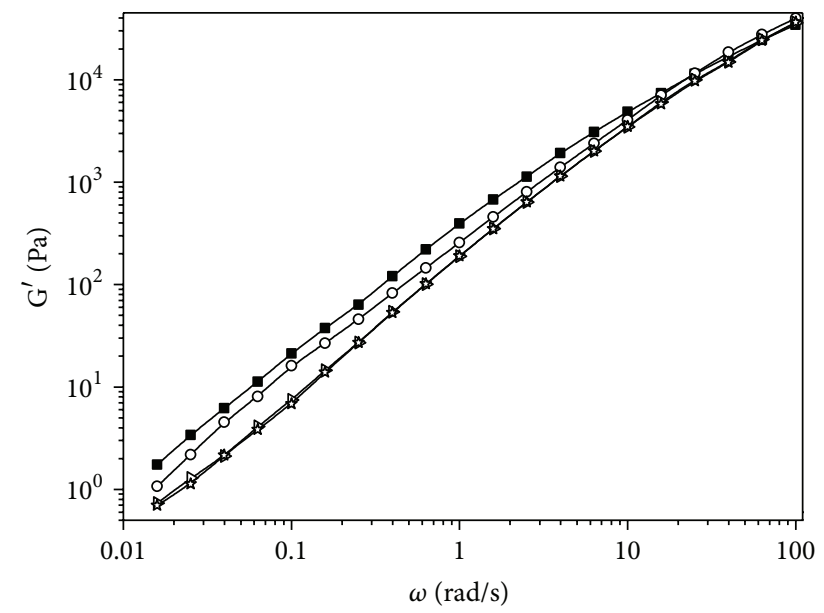

(a)

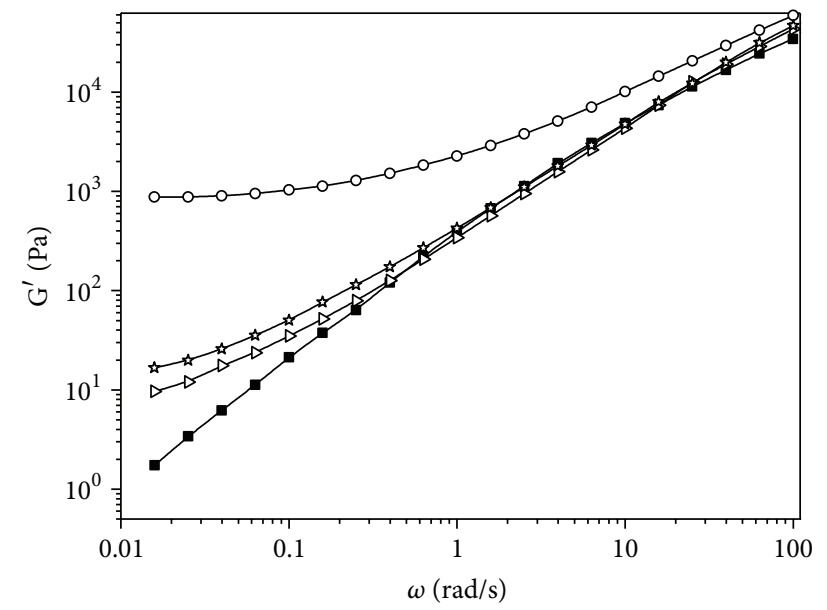

(c)

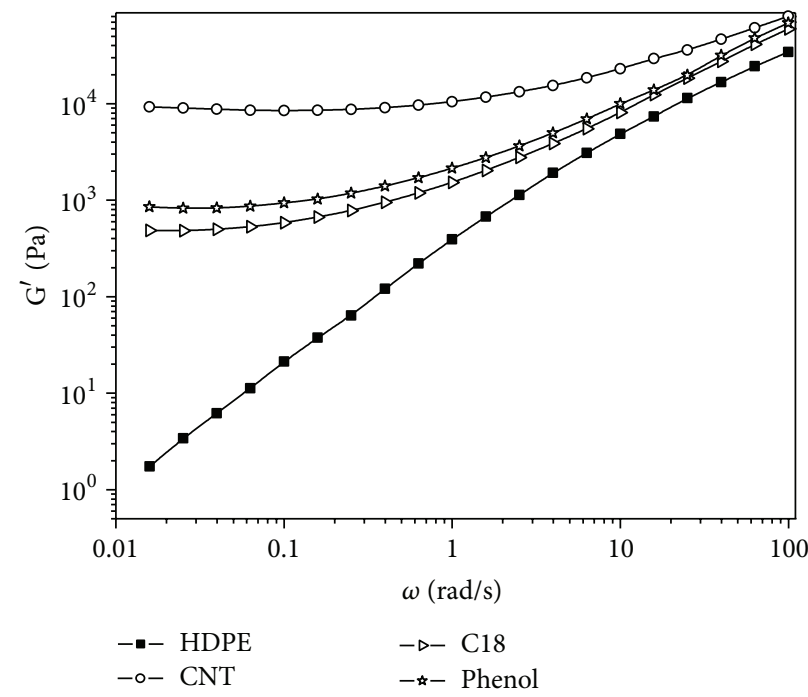

(e)

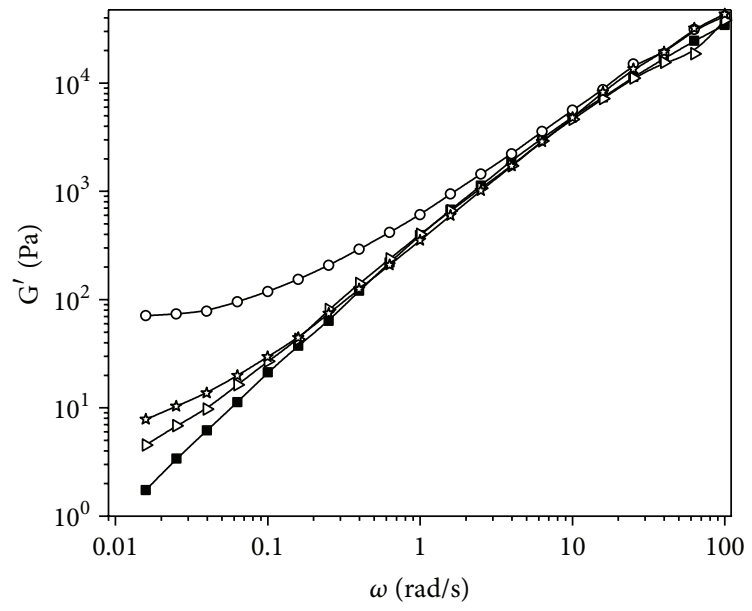

(b)

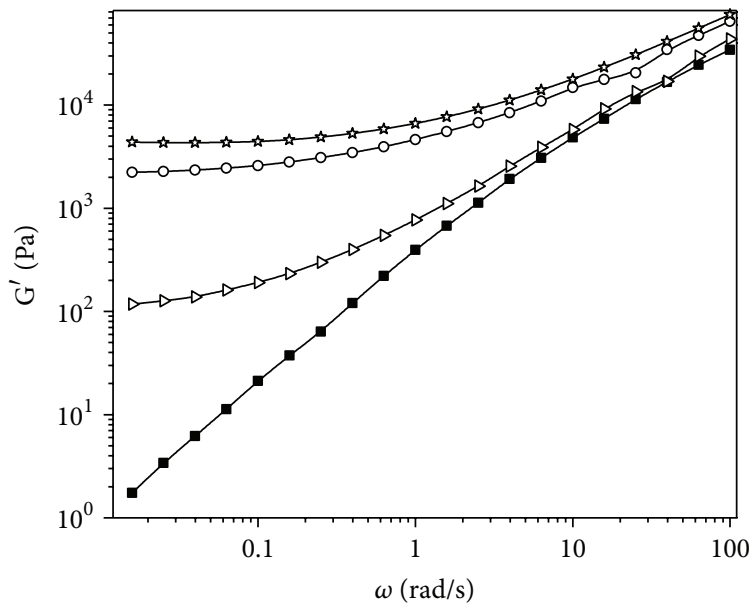

(d)

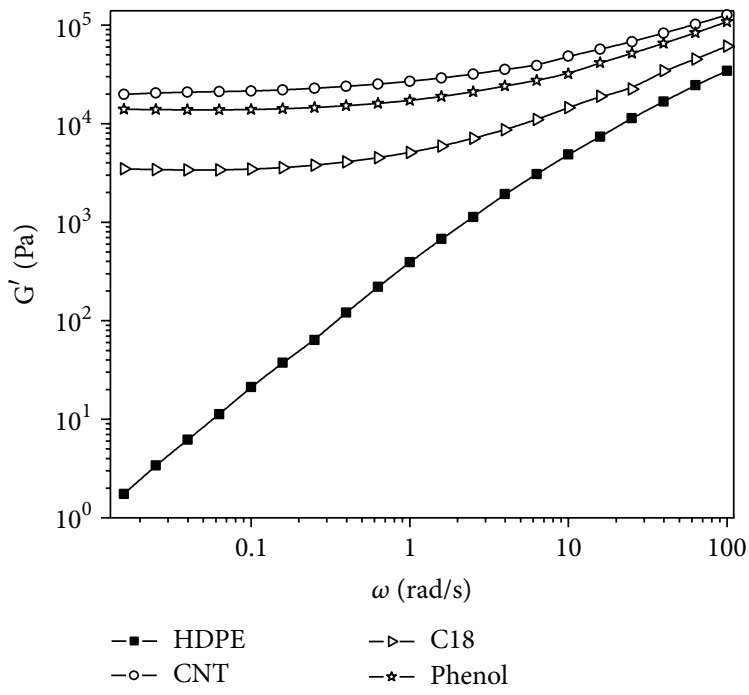

(f)

FIGURE 4: Variation of storage modulus of HDPE composites with frequency. (a) 1, (b) 2, (c) 3, (d) 4, (e) 5, and (f) 7 wt\% loading of nanofiller. 


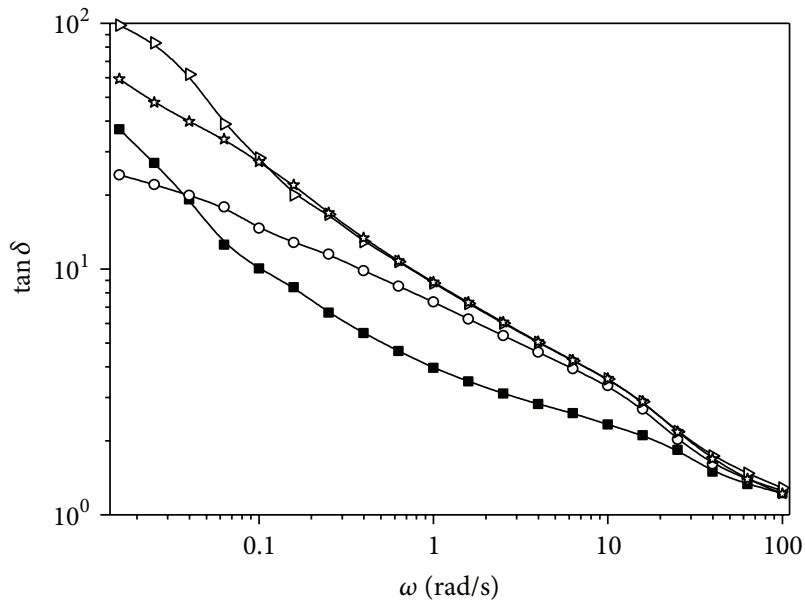

(a)

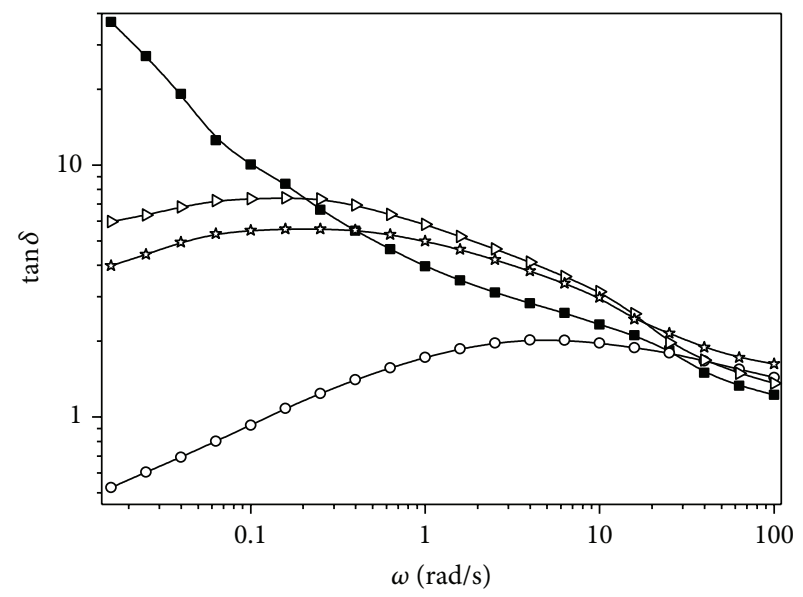

(c)

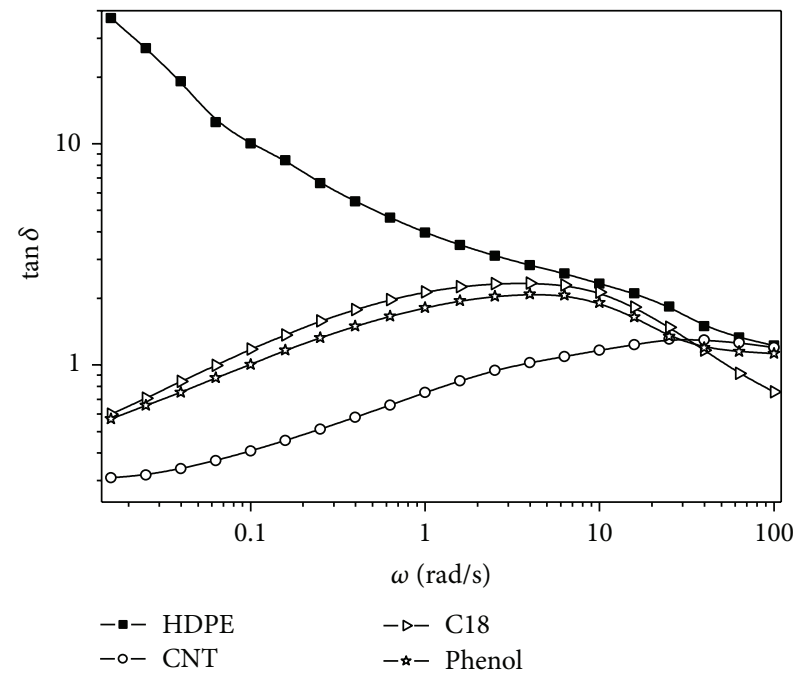

(e)

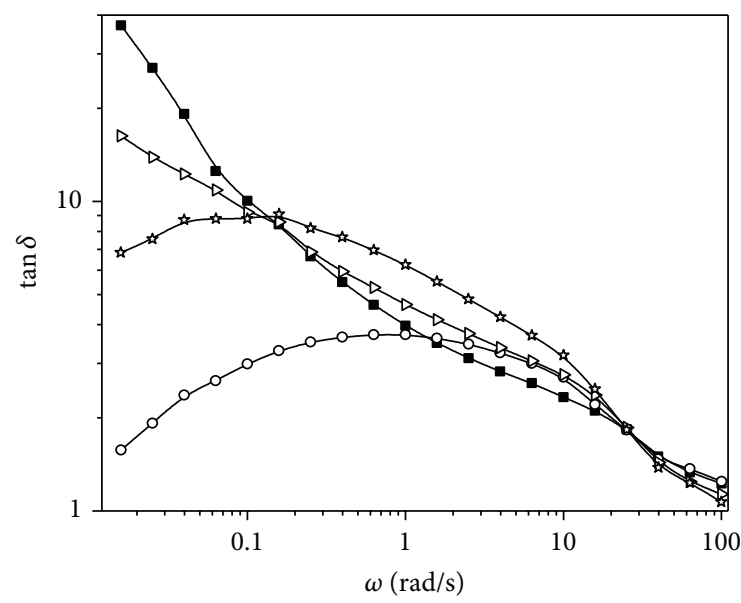

(b)

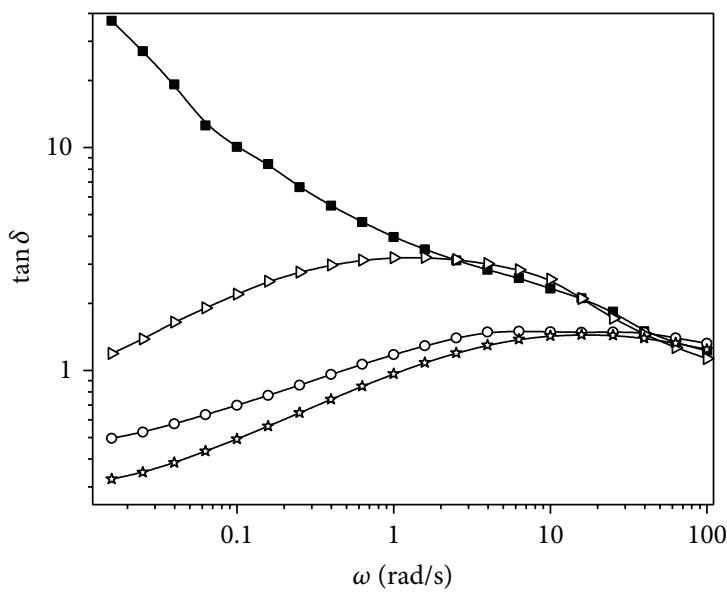

(d)

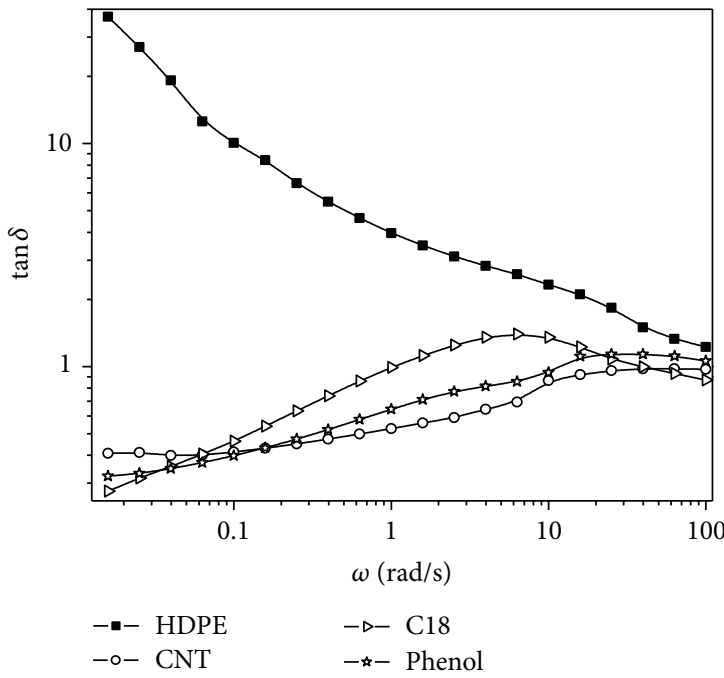

(f)

FIGURE 5: Variation of $\tan \delta$ of HDPE composites with frequency. (a) 1, (b) 2, (c) 3, (d) 4, (e) 5, and (f) 7 wt\% loading of nanofiller. 


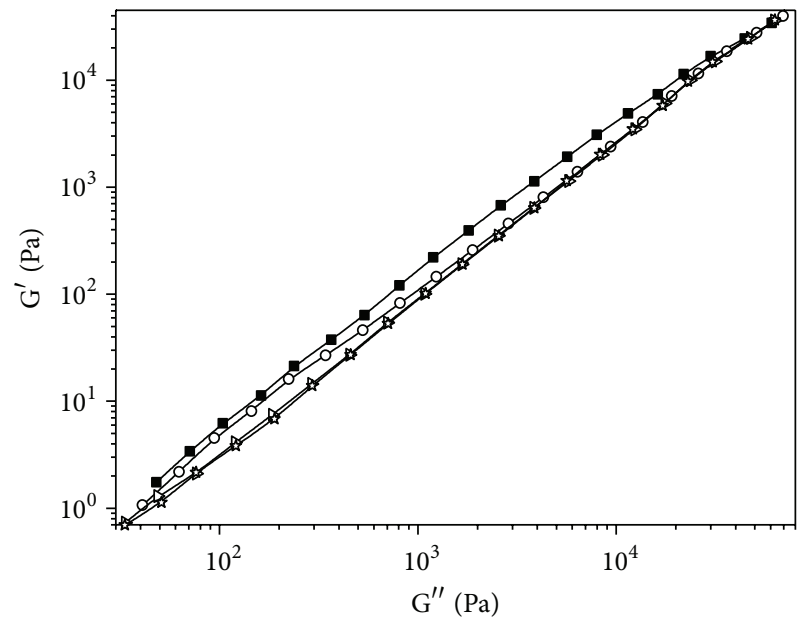

(a)

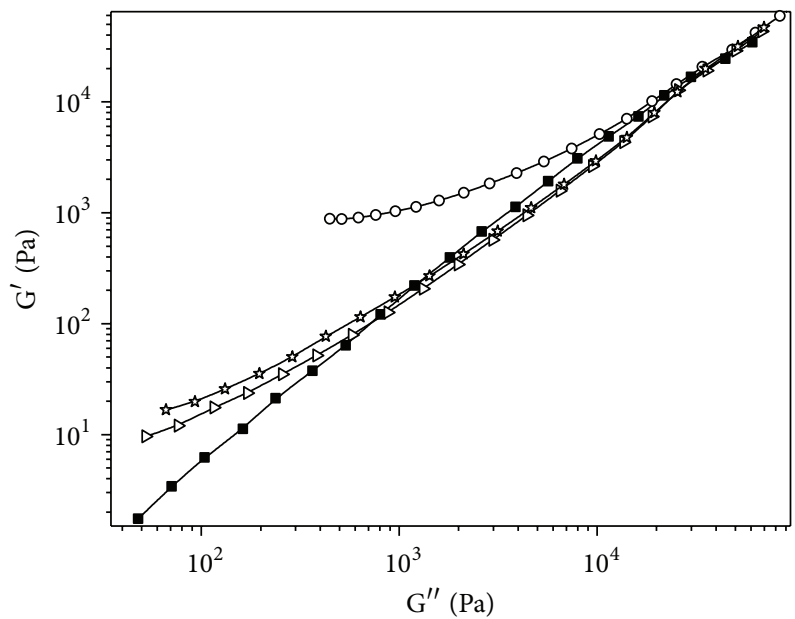

(c)

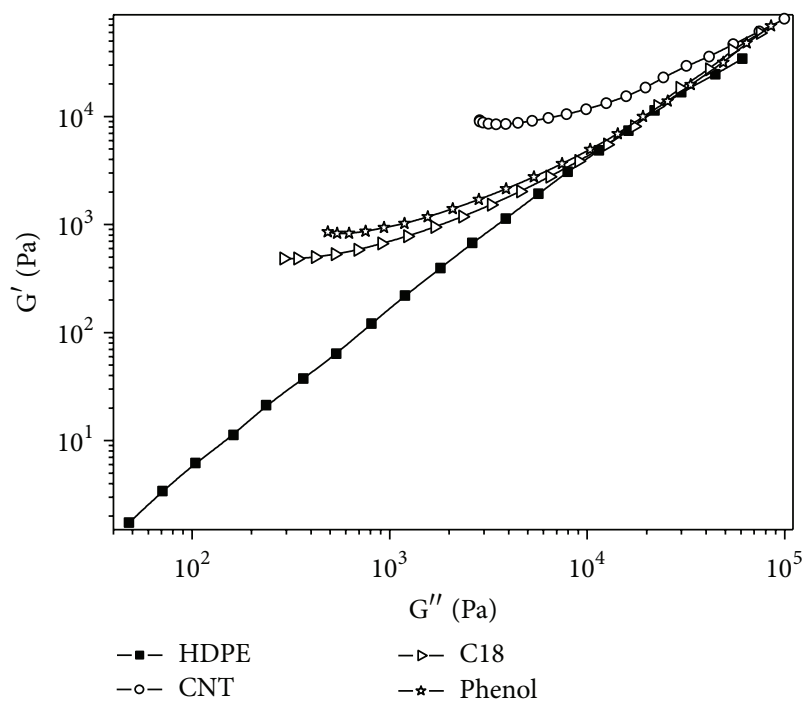

(e)

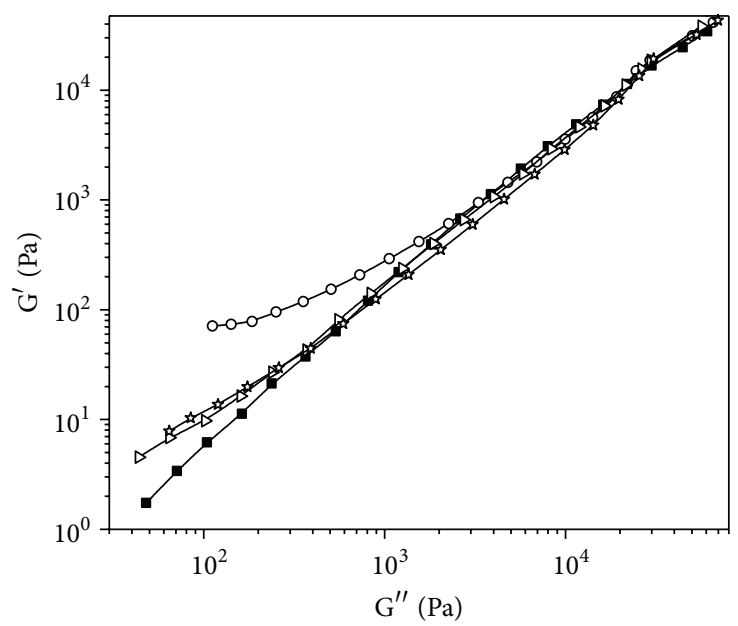

(b)

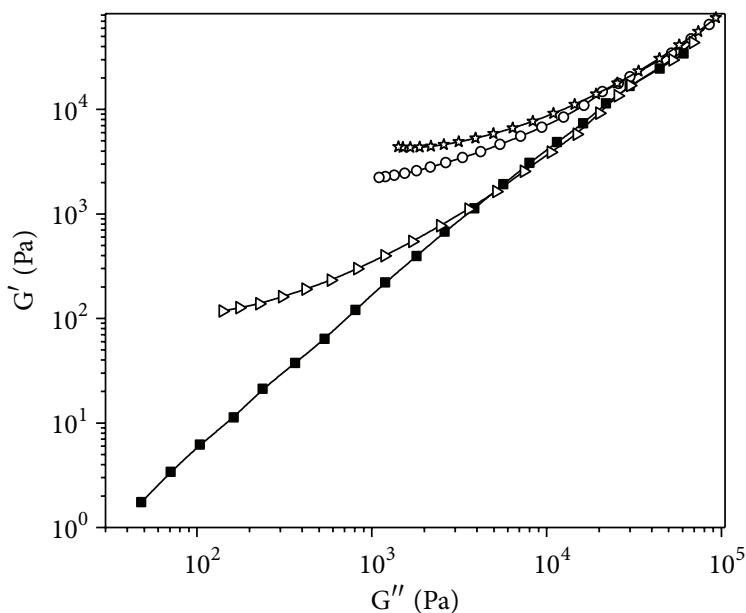

(d)

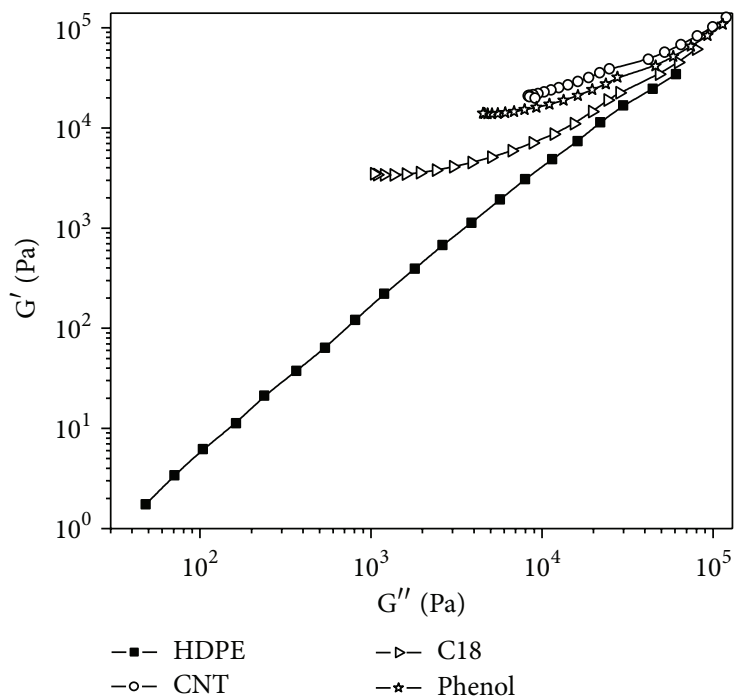

(f)

Figure 6: Modified Cole-Cole plots of HDPE composites. (a) 1, (b) 2, (c) 3, (d) 4, (e) 5, and (f) 7 wt\% loading of nanofiller. 


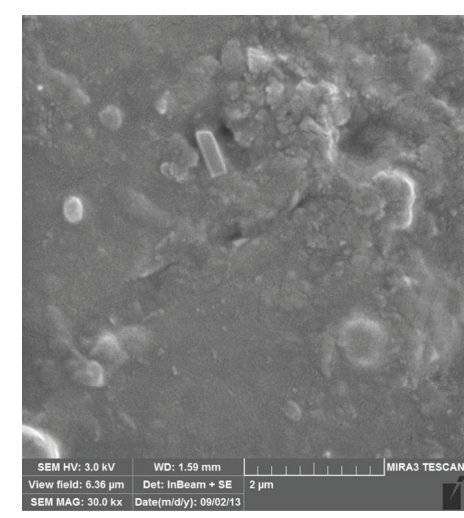

(a)

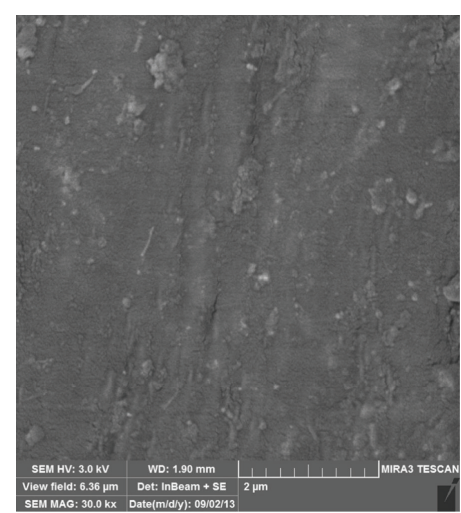

(c)

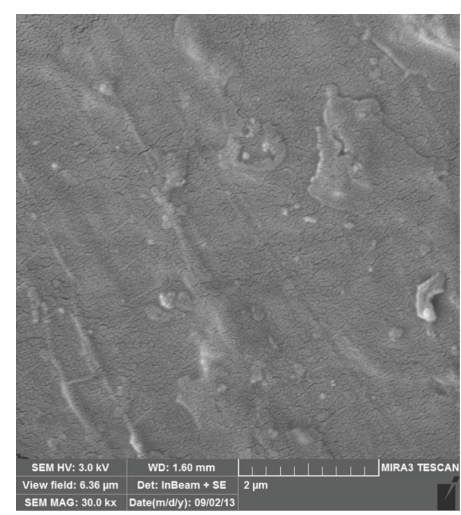

(e)

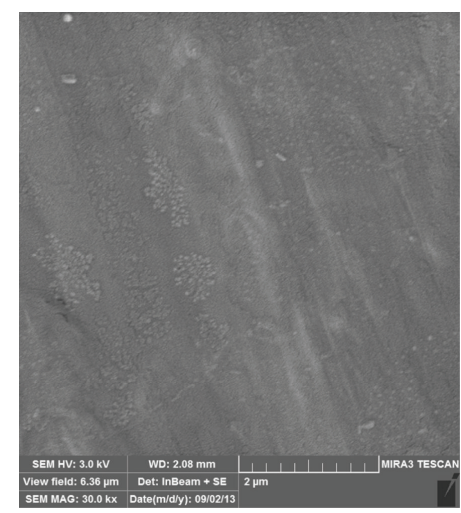

(b)

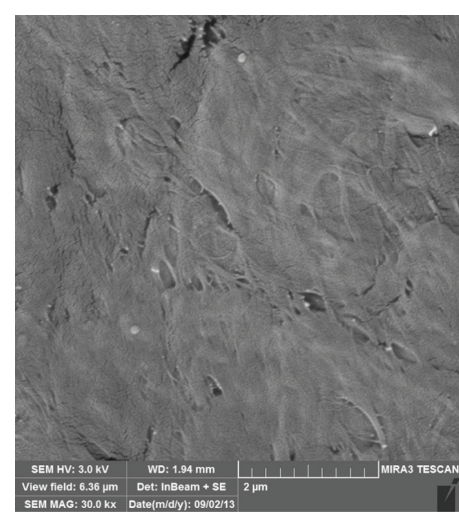

(d)

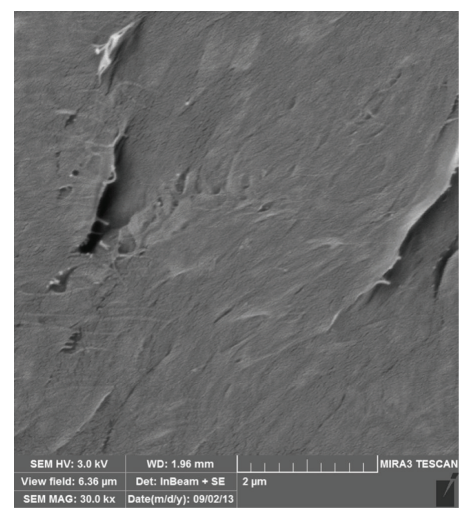

(f)

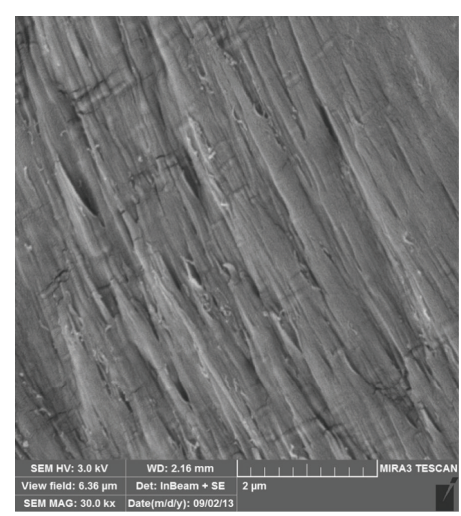

(g)

FIGURE 7: SEM images of the net HDPE, pristine CNT, and functionalized CNT. (a) net HDPE, (b) $1 \mathrm{wt} \%$ CNT, (c) $7 \mathrm{wt} \% \mathrm{CNT}$, (d) $1 \mathrm{wt} \% \mathrm{Cl}$, (e) 7 wt\% C18, (f) 1 wt $\%$ phenol, and (g) 7 wt\% phenol. 


\section{Discussion}

In reference to Figure 1, the decrease in viscosity at $1 \mathrm{wt} \%$ is believed to be due to the increase in disentanglement of the polymer chains induced by the nanofiller, acting as streamliners for the flow of polymer chains as reported earlier [25-27]. The reduction in viscosity is pronounced in the case of functionalized CNT, and it is believed that the deaggregation of the nanoparticles contributes further to the disentanglement process. It is also interesting to observe that the range of the frequency where the viscosity is constant, the Newtonian plateau viscosity, increases due to the presence of pristine and functionalized CNT in the same order of that of the percent reduction of the viscosity. In the high frequency region, however, the changes in the viscosity follow different trend and both pristine and functionalized CNT show higher viscosity than the neat polymer, due to the hydrodynamic effect. It is believed that chemical modification of CNT surface assists in deaggregation of the nanoparticles and subsequent disentanglement of the polymer chains and a drop in viscosity, as compared to the pristine CNT. Moreover, the functionalization may lead to the decrease in the aspect ratio of CNT due to the de-aggregation of the tubules by the functionalizing agents $[28,29]$.

As the nano filler loading increases to $2 \mathrm{wt} \%$, the proposed hydrodynamic factor plays a dominant role in controlling the viscosity in the whole range of frequency studied. The same trend is observed at $3 \mathrm{wt} \%$ loading. But in the case of functionalized CNT, the de-aggregation of the filler particles counterbalances the hydrodynamic factor. It is also evident that the functionalization of CNT causes greater decrease in viscosity than the pristine CNT and the viscosity follows the order, neat polymer $<$ C18 modified CNT $<$ phenol modified $\mathrm{CNT}<\mathrm{CNT}$. The effect becomes pronounced as the nano filler loading increases to 5 and $7 \mathrm{wt} \%$. Figure 2 shows that the viscosity ratio increases with the increase in nanofiller concentration and the relative increase is less in the case of functionalized CNT, as compared to pristine CNT.

Although the reduction in viscosity by the addition of rigid fillers in a matrix is uncommon, there are reports on the contrary. Recently, similar observation was made by Thomas et al. in the case of isotactic-polypropylene (iPP)/CNT composites [30]. However, the drop in viscosity for the present system of HDPE/CNT is observed at $1 \mathrm{wt} \%$ loading, whereas in the case of $\mathrm{PP} / \mathrm{CNT}$, the drop in viscosity was observed at a loading of $0.5 \mathrm{wt} \%$ and below and the same phenomenon was not observed at $1 \mathrm{wt} \%$ loading. The presently used HDPE grade has high molecular mass with a linear structure, which is likely to increase the entanglements of the polymer chains, and thus the loading of CNT needed for reduction in viscosity is likely to be greater in HDPE than that in iPP. This is also in agreement with a previous report by Adesina et al. on processability of nanoclay-filled linear and branched grades of polyethylene [31]. A few more similar observations were reported related to linear polystyrene (PS) composites filled with organic nanoparticles [17-19]. Also, Jain et al. reported decrease in viscosity for silica filled PP composites [32].
The results of steady shear viscosity measurements (Figure 3) are in conformity with the above observations on changes in dynamic viscosity on incorporation of nano filler, and it can be argued that Cox-Merz rule is followed in this type of composite system. The $1 \mathrm{wt} \%$ loading of the nano filler shows a reduction in the steady shear viscosity, and the effect is pronounced in the case of functionalized CNT. As the filler loading increases to 2 and $3 \mathrm{wt} \%$, irrespective of the type of nano filler, the viscosity of the composite overshoots the viscosity of neat HDPE. But the chemically modified CNT shows lower viscosity than the pristine CNT in all loadings. Ma et al. have reported on the rheological modeling of pristine and chemically modified CNT aggregate suspensions, and the increase in viscosity at higher loadings was attributed to the formation of filler network [33, 34].

Figure 4 shows that at $1 \mathrm{wt} \%$ loading of the nano filler, there is no clear plateau in the plots of storage modulus versus frequency in the low frequency region. But as the pristine CNT concentration increases to 2 and $3 \mathrm{wt} \%$, a plateau is observed, which is indicative of filler network formation. The plateau in $\mathrm{G}^{\prime}$ values in the low frequency range has been cited by several researchers for polymer nanocomposites, including nanoclay-filled as well as carbon nanotubes filled composites, and they attributed this behavior to the formation of physical networks of the nanofillers inside the host matrix $[15,16,35-38]$. For nanoclay-filled polymers, for example, Solomon et al. examined the melt-state rheology of nanoclay/polypropylene system at various clay loadings [35]. Above clay loadings of $2.0 \mathrm{wt} \%$ the nanocomposite materials exhibited apparent low-frequency plateau in $G^{\prime}$, and they concluded that the rheological percolation threshold for the formation of network was at $2.0 \mathrm{wt} \%$ loading.

However, no such plateau is not observed in the case of functionalized CNT at $3 \mathrm{wt} \%$ loading. As the CNT loading increases further beyond $3 \mathrm{wt} \%$ (i.e., 4, 5 and $7 \mathrm{wt} \%$ ), even the functionalized CNT shows plateau in the low frequency region, indicating network formation, as observed in the case of pristine CNT. Therefore, it can be suggested that the rheological percolation threshold for the HDPE/CNT system is strongly dependant on the functionalization of CNT and for the pristine CNT it is around $3 \mathrm{wt} \%$ but for the functionalized CNT it is around $7 \mathrm{wt} \%$.

In reference to Figure 5, in the low frequency range for the filler loadings of 5 and $7 \mathrm{wt} \%$ (Figures 5(e) and 5(f)), $\tan \delta$ is less than unity, and it increases with respect to frequency in the low frequncy range till it reaches a maximum, which could be ascribed to the formation of CNT network. This effect is also slightly noticeable at $4 \mathrm{wt} \%$ but less pronounced in the case of $3 \mathrm{wt} \%$ loading of nano filler, particularly in the case of functionalized CNT (Figures 5(c) and 5(d)). However, at $1 \mathrm{wt} \%$ loading of the nano filler this behaviour is not observed for both pristine and functionalized CNT (Figure 5(a)). The observation on increase in $\tan \delta$ with increase in $\omega$ in the low frequency range has been observed earlier in the case of several polymer nanocomposites and has been explained on the basis of formation of physical network of the nanofillers in the host polymer matrix at and higher 
than the rheological percolation threshold $[15,38]$. Accordingly, we are of the opinion that the rheological percolation threshold of pristine CNT-HDPE system is around 3 and $4 \mathrm{wt} \%$, whereas the same for the functionalized CNT-HDPE systems is around $7 \mathrm{wt} \%$. The decrease in slope in the plots of $G^{\prime}$ versus $G^{\prime \prime}$ (Figure 6) can be attributed to the formation of physical network in the host matrix as has been suggested by Pötschke et al. and Prashanta et al. [39, 40].

\section{Conclusion}

The dynamic viscosity, steady shear viscosity and storage modulus of HDPE decrease at low loading (i.e., 1 wt\%) of both pristine CNT and functionalized CNT, and the decrease follows the order, pristine $\mathrm{CNT}<$ phenol functionalized CNT < C18 functionalized CNT. As the nanofiller loading is increased to 2 and $3 \mathrm{wt} \%$, the rheological behavior changes and the viscosity and storage modulus increase and overshoot the values for neat HDPE. The effect becomes pronounced as the nanofiller loading is increased to 4,5 , and $7 \mathrm{wt} \%$. The rheological results are indicative of formation of filler networks in the polymer matrix and the rheological percolation threshold for the network to form is strongly dependant on the functionalization of CNT. For example, for the unfunctionalized CNT the percolation threshold is around $4 \mathrm{wt} \%$, but for functionalized CNT, it is around $7 \mathrm{wt} \%$. The surface morphologies of CNT and functionalized CNT at $1 \mathrm{wt} \%$ loading showed good dispersion while at $7 \mathrm{wt} \%$ loading, dispersion was also achieved, but there are few regions with agglomeration of CNT.

\section{References}

[1] K. Chrissafis, K. M. Paraskevopoulos, I. Tsiaoussis, and D. Bikiaris, "Comparative study of the effect of different nanoparticles on the mechanical properties, permeability, and thermal degradation mechanism of HDPE," Journal of Applied Polymer Science, vol. 114, no. 3, pp. 1606-1618, 2009.

[2] G. Sui, W. H. Zhong, X. Ren, X. Q. Wang, and X. P. Yang, "Structure, mechanical properties and friction behavior of UHMWPE/HDPE/carbon nanofibers," Materials Chemistry and Physics, vol. 115, no. 1, pp. 404-412, 2009.

[3] Q. Dong, Q. Zheng, M. Du, and M. Zhang, “Temperaturedependence of dynamic rheological properties for high-density polyethylene filled with graphite," Journal of Materials Science, vol. 40, no. 13, pp. 3539-3541, 2005.

[4] W. Zheng, X. Lu, and S.-C. Wong, "Electrical and mechanical properties of expanded graphite-reinforced high-density polyethylene," Journal of Applied Polymer Science, vol. 91, no. 5, pp. 2781-2788, 2004.

[5] M. A. Osman and A. Atallah, "Effect of the particle size on the viscoelastic properties of filled polyethylene," Polymer, vol. 47, no. 7, pp. 2357-2368, 2006.

[6] Y. Tang, C. Yang, P. Gao, L. Ye, C. Zhao, and W. Lin, "Rheological study on high-density polyethylene/organoclaycomposites," Polymer Engineering and Science, vol. 51, no. 1, pp. 133-142, 2011.

[7] J. F. Vega, J. Martínez-Salazar, M. Trujillo et al., "Rheology, processing, tensile properties, and crystallization of polyethylene/carbon nanotube nanocomposites," Macromolecules, vol. 42, no. 13, pp. 4719-4727, 2009.
[8] J. Sandler, M. S. P. Shaffer, T. Prasse, W. Bauhofer, K. Schulte, and A. H. Windle, "Development of a dispersion process for carbon nanotubes in an epoxy matrix and the resulting electrical properties," Polymer, vol. 40, no. 21, pp. 5967-5971, 1999.

[9] M. S. P. Shaffer and A. H. Windle, "Fabrication and characterization of carbon nanotube/poly (vinyl alcohol) composites," Advanced Materials, vol. 11, no. 11, pp. 937-941, 1999.

[10] M. Bratcher, B. Gersten, H. Ji, and J. Mays, "Study in the dispersion of carbon nanotubes," MRS Proceedings, vol. 706, 2001.

[11] X. Gong, J. Liu, S. Baskaran, R. D. Voise, and J. S. Young, "Surfactant-assisted processing of carbon nanotube/polymer composites," Chemistry of Materials, vol. 12, no. 4, pp. 10491052,2000

[12] Y. Zou, Y. Feng, L. Wang, and X. Liu, "Processing and properties of MWNT/HDPE composites," Carbon, vol. 42, no. 2, pp. 271$277,2004$.

[13] H. Ha, S. C. Kim, and K. Ha, "Morphology and properties of polyamide/multi-walled carbon nanotube composites," Macromolecular Research, vol. 18, no. 7, pp. 660-667, 2010.

[14] M. A. Osman and A. Atallah, "Interparticle and particle-matrix interactions in polyethylene reinforcement and viscoelasticity," Polymer, vol. 46, no. 22, pp. 9476-9488, 2005.

[15] T. McNally, P. Pötschke, P. Halley et al., "Polyethylene multiwalled carbon nanotube composites," Polymer, vol. 46, no. 19, pp. 8222-8232, 2005.

[16] O. Valentino, M. Sarno, N. G. Rainone et al., "Influence of the polymer structure and nanotube concentration on the conductivity and rheological properties of polyethylene/CNT composites," Physica E, vol. 40, no. 7, pp. 2440-2445, 2008.

[17] M. E. Mackay, T. T. Dao, A. Tuteja et al., "Nanoscale effects leading to non-einstein-like decrease in viscosity," Nature Materials, vol. 2, no. 11, pp. 762-766, 2003.

[18] A. Tuteja, M. E. Mackay, C. J. Hawker, and B. Van Horn, "Effect of ideal, organic nanoparticles on the flow properties of linear polymers: non-einstein-like behavior," Macromolecules, vol. 38, no. 19, pp. 8000-8011, 2005.

[19] M. E. Mackay, A. Tuteja, P. M. Duxbury et al., "General strategies for nanoparticle dispersion," Science, vol. 311, no. 5768, pp. 1740 1743, 2006.

[20] T. C. Merkel, B. D. Freeman, R. J. Spontak et al., "Ultrapermeable, reverse-selective nanocomposite membranes," Science, vol. 296, no. 5567, pp. 519-522, 2002.

[21] S. B. Kharchenko, J. F. Douglas, J. Obrzut, E. A. Grulke, and K. B. Migler, "Flow-induced properties of nanotube-filled polymer materials," Nature Materials, vol. 3, no. 8, pp. 564-568, 2004.

[22] J. Ren and R. Krishnamoorti, "Nonlinear viscoelastic properties of layered-silicate-based intercalated nanocomposites," Macromolecules, vol. 36, no. 12, pp. 4443-4451, 2003.

[23] S. P. Thomas, A. A. Abdullateef, M. A. Al-Harthi et al., "Electrical properties of natural rubber nanocomposites: effect of 1octadecanol functionalization of carbon nanotubes," Journal of Materials Science, vol. 47, no. 7, pp. 3344-3349, 2012.

[24] S. P. Thomas, A. A. Abdullateef, M. A. Al-Harthi et al., "Effect of phenol functionalization of carbon nanotubes on properties of natural rubber nanocomposites," Journal of Applied Polymer Science, vol. 124, no. 3, pp. 2370-2376, 2012.

[25] J. S. Oh, K. H. Ahn, and J. S. Hong, "Dispersion of entangled carbon nanotube by melt extrusion," Korea Australia Rheology Journal, vol. 22, no. 2, pp. 89-94, 2010. 
[26] J. Li, P. C. Ma, W. S. Chow, C. K. To, B. Z. Tang, and J.-K. Kim, "Correlations between percolation threshold, dispersion state, and aspect ratio of carbon nanotubes," Advanced Functional Materials, vol. 17, no. 16, pp. 3207-3215, 2007.

[27] P.-C. Ma and J.-K. Kim, Carbon Nanotubes for Polymer Reinforcement, CRC Press, Boca Raton, Fla, USA, 2011.

[28] G. K. Batchelor and J. T. Green, "hydrodynamic interaction of two small freely-moving spheres in a linear flow field," Journal of Fluid Mechanics, vol. 56, no. 2, pp. 375-400, 1972.

[29] G. K. Batchelor and J. T. Green, "The determination of the bulk stress in a suspension of spherical particles to order $c^{2}$ ", Journal of Fluid Mechanics, vol. 56, no. 3, pp. 401-427, 1972.

[30] S. P. Thomas, S. A. Girei, A. A. Al-Juhani, K. Mezghani, S. K. De, and M. A. Atieh, "Effect of phenol functionalized carbon nanotube on mechanical, dynamic mechanical, and thermal properties of isotactic polypropylene nanocomposites," Polymer Engineering and Science, vol. 52, no. 3, pp. 525-531, 2012.

[31] A. A. Adesina, A. A. Al-Juhani, N. Tabet, A. Ul-Hamid, and I. A. Hussein, "Rheology and enhancement of extrusion of linear and branched polyethylenes using low amount of organoclay," Journal of Applied Polymer Science, vol. 126, no. 2, pp. 713-723, 2012.

[32] S. Jain, J. G. P. Goossens, G. W. M. Peters, M. Van Duin, and P. J. Lemstra, "Strong decrease in viscosity of nanoparticle-filled polymer melts through selective adsorption," Soft Matter, vol. 4, no. 9, pp. 1848-1854, 2008.

[33] W. K. A. Ma, F. Chinesta, A. Ammar, and M. R. MacKley, "Rheological modeling of carbon nanotube aggregate suspensions," Journal of Rheology, vol. 52, no. 6, pp. 1311-1330, 2008.

[34] A. W. K. Ma, F. Chinesta, and M. R. MacKley, “The rheology and modeling of chemically treated carbon nanotubes suspensions," Journal of Rheology, vol. 53, no. 3, pp. 547-577, 2009.

[35] M. J. Solomon, A. S. Almusallam, K. F. Seefeldt, A. Somwangthanaroj, and P. Varadan, "Rheology of polypropylene/clay hybrid materials," Macromolecules, vol. 34, no. 6, pp. 1864-1872, 2001.

[36] M.-K. Seo and S.-J. Park, "Electrical resistivity and rheological behaviors of carbon nanotubes-filled polypropylene composites," Chemical Physics Letters, vol. 395, no. 1-3, pp. 44-48, 2004.

[37] S. H. Lee, M. W. Kim, S. H. Kim, and J. R. Youn, "Rheological and electrical properties of polypropylene/MWCNT composites prepared with MWCNT masterbatch chips," European Polymer Journal, vol. 44, no. 6, pp. 1620-1630, 2008.

[38] Q. Zhang, D. R. Lippits, and S. Rastogi, "Dispersion and rheological aspects of SWNTs in ultrahigh molecular weight polyethylene," Macromolecules, vol. 39, no. 2, pp. 658-666, 2006.

[39] P. Pötschke, T. D. Fornes, and D. R. Paul, "Rheological behavior of multiwalled carbon nanotube/polycarbonate composites," Polymer, vol. 43, no. 11, pp. 3247-3255, 2002.

[40] K. Prashantha, J. Soulestin, M. F. Lacrampe, M. Claes, G. Dupin, and P. Krawczak, "Multi-walled carbon nanotube filled polypropylene nanocomposites based on masterbatch route: improvement of dispersion and mechanical properties through PP-g-MA addition," Express Polymer Letters, vol. 2, no. 10, pp. 735-745, 2008. 

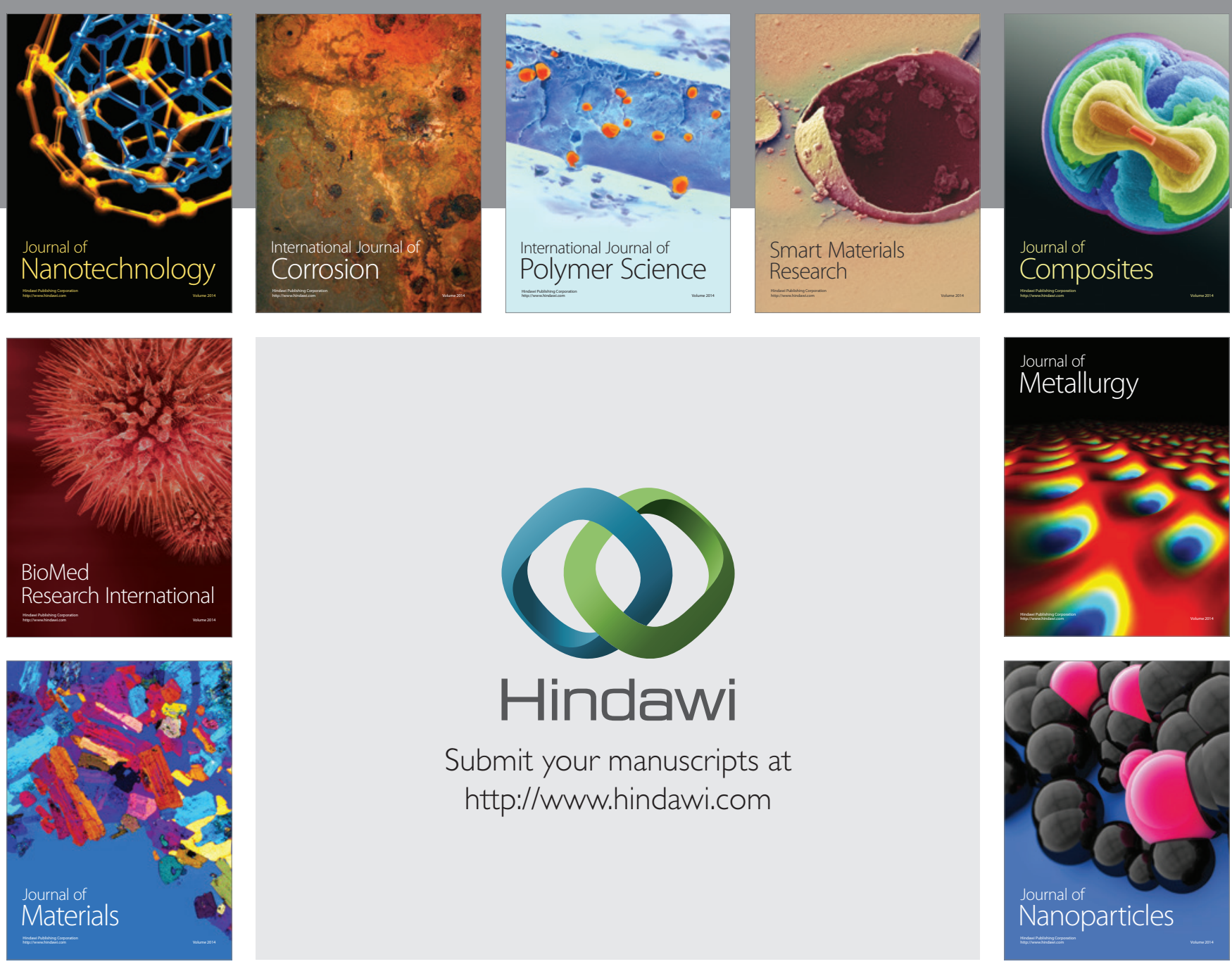

Submit your manuscripts at http://www.hindawi.com
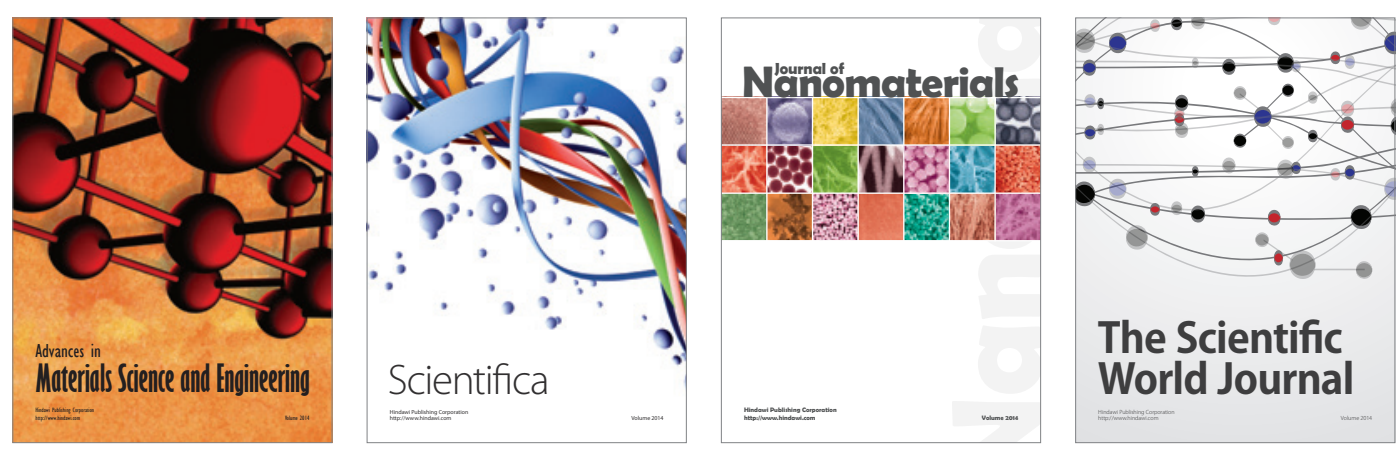

\section{The Scientific World Journal}
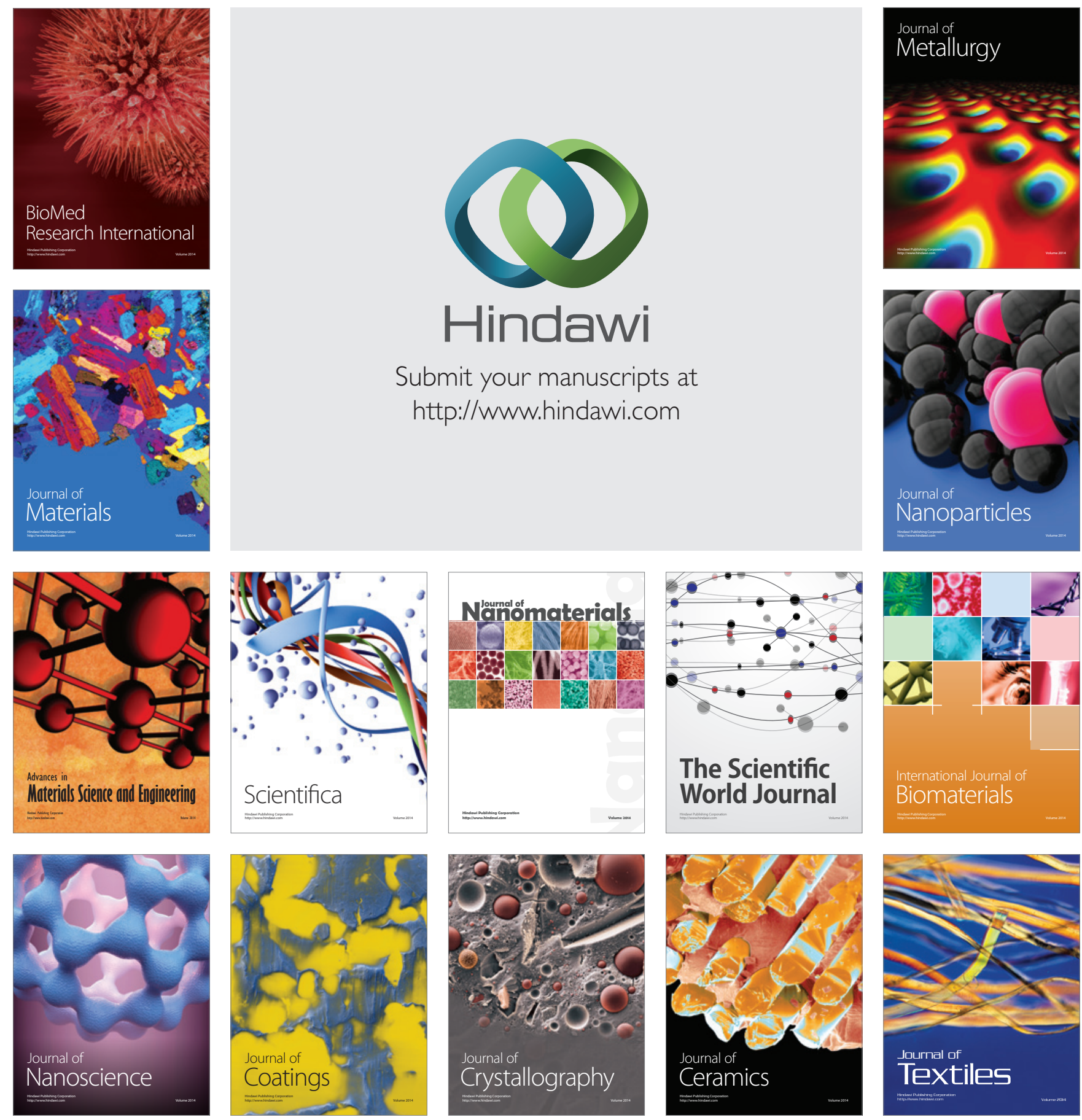